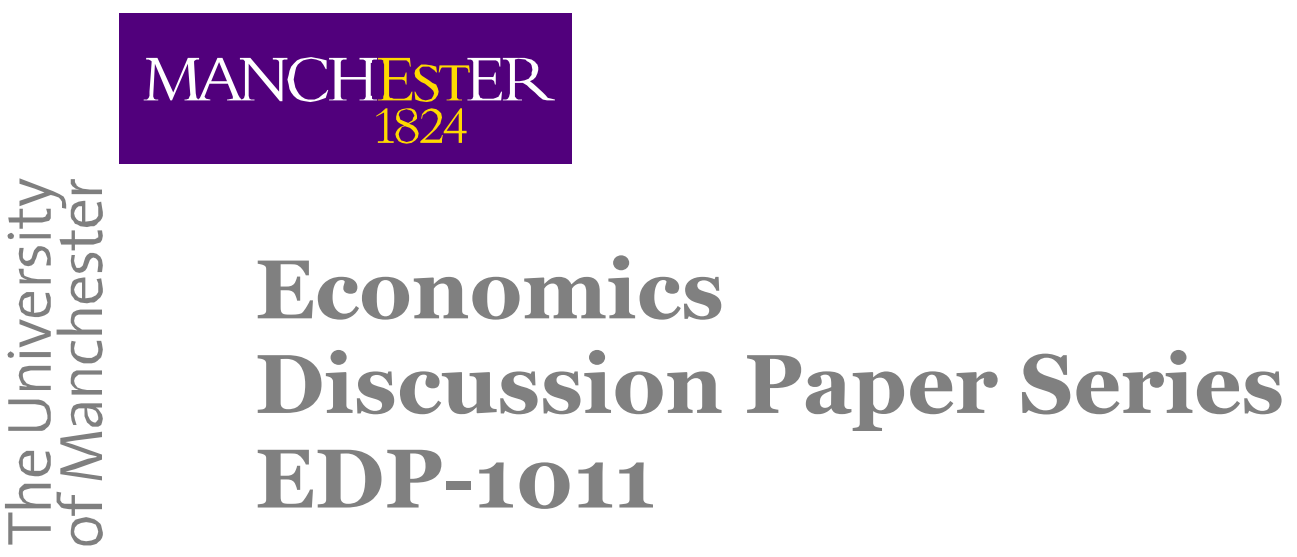

\title{
Pro-Poor Growth, Poverty and Inequality in Rural Vietnam
}

Woojin Kang and Katsushi S. Imai

June 2010

Economics

School of Social Sciences

The University of Manchester

Manchester M13 9PL 


\title{
Pro-Poor Growth, Poverty and Inequality in Rural Vietnam*
}

\author{
Woojin Kang ${ }^{\dagger}$ \\ Economics, School of Social Sciences, University of Manchester, UK \\ Woojin.Kang1@gmail.com \\ $\&$ \\ Katsushi S. Imai \\ Economics, School of Social Sciences, University of Manchester, UK \& \\ RIEB, Kobe University, Japan \\ Katsushi.Imai@manchester.ac.uk
}

$28^{\text {th }}$ May 2010

\begin{abstract}
This study explores the effects of Vietnam's transition on the welfare of different ethnic groups in rural Vietnam. It draws on three rounds of household surveys, VHLSS 2002, 2004 and 2006. It is first observed that the pace of poverty reduction for minorities surpassed the majority over the period 2002 to 2006, although poor people were still concentrated in the minority groups. Secondly, the disparity of living standards has been widening. In particular, inequality in both the majority and minority increased over the periods. Thirdly, the study shows that the pure effect of economic growth on poverty is estimated to have been greater if inequality remained constant. It is noted that the impacts of economic growth vary depending on which ethnic group a household belongs to. Finally, it is also confirmed from regression decompositions of within inequality that the main driver of inequality is not identical among different ethnic groups. Given the diversity across ethnic groups, we can conclude that the governmental policy aiming at equal access to infrastructure and more equal distribution of assets, such as land, for ethnic minority groups would lead to more equal distribution of consumption and poverty reduction of those groups. Also, consideration of local needs of each ethnic minority group would be necessary in designing and implementing public policies given the heterogeneous socioeconomic circumstances surrounding each ethnic minority group.
\end{abstract}

Key words: Vietnam, Ethnic minority, Growth, Poverty, Inequality, Decomposition JEL codes: C21, I32, P36

* Acknowledgements

We are grateful to the financial support of the small grant from DFID and Chronic Poverty Research Centre at the University of Manchester in the UK. Research support from RIEB, Kobe University for the second author is greatly acknowledged. We have benefited from valuable comments from Raghav Gaiha, Takahiro Sato and participants in the seminar at Manchester and the Kyung Hee University and the United Nations' international conference 'World Civic Forum 2009 - Building Our Humanitarian Planet' in Korea in 2009. The views expressed are, however, those of the authors' and do not necessarily represent those of the organisations to which they are affiliated.

$\dagger$ Corresponding Author:

Woojin Kang, Economics, School of Social Sciences, University of Manchester, Oxford Road, Manchester M13 9PL, UK, Phone: +44-(0)778-685-8456; E-mail: Woojin.Kang1@ gmail.com 


\section{Pro-Poor Growth, Poverty and Inequality in Rural Vietnam}

\section{Introduction}

Vietnam has shown a distinguished performance in poverty alleviation since the Doi moi, economic reforms were enacted in 1986. As an early achiever of UN's Millennium Development Goals (MDGs), Vietnam has, in recent years, been maintaining steady progress towards its own, and more specific, targets - the Vietnam Development Goals (VDGs). The poverty headcount ratio has plummeted in recent years: from $57.1 \%$ in 1993, $37.3 \%$ in 1998, $28.8 \%$ in $2002,19.5 \%$ in 2004 , to $16.0 \%$ in $2006^{1}$. However these aggregate numbers, disguise the chronic poverty of Vietnam's ethnic minorities and, for the VDGs, enhancing the living standards of these groups will prove to be a more demanding challenge, as they still account for a disproportionately large share of the poor ${ }^{2}$. Furthermore, Vulnerability as Expected Poverty (VEP), for all of the minority groups is also much higher and remains (in 2006) well above that of the majority (see Chaudhuri, Jalan and Suryahadi, 2002) ${ }^{3}$. This study focuses on the changes of poverty, inequality and growth as they apply to minority communities in rural Vietnam during the latter years of the transition. It aims to both chart the changes over the period since 2002, and so offer insights on the effectiveness of government and donor policy responses.

\footnotetext{
${ }^{1}$ Poverty rates used here are based on the international poverty line which was devised by the Vietnamese General Statistics Office (GSO) to reflect food expenditure for an intake of 2100 calories a day and corresponding non-food expenditure. The basket of food and non-food items is determined by the consumption patterns of the third quintile of households in terms of per capita expenditure. The poverty lines were VND 1.16 million per person per year in 1993, VND 1.79 million in 1998, VND 1.92 million in 2002, VND 2.07 million in 2004 and 2.56 million in 2006.

${ }^{2}$ According to our study, among the poor households whose consumption level was below the poverty threshold in at least one period, $25 \%$ are estimated to be chronically poor during the period of 2002-2006. In particular, $37 \%$ of the ethnic minority groups are estimated as the chronically poor while only $4.4 \%$ of the persistent poor in the majority being observed.

${ }^{3}$ Drawing upon the 2006 Vietnam Household Living Standards Survey (VHLSS), the estimate of VEP for the rural minority groups was 0.44 , i.e. the minority groups has, on average, $40 \%$ of probability of falling into poverty in the future. This is highly contrasted with $4.2 \%$ of probability for the majority group.
} 
Vietnam is a multi-ethnic society, consisting of 54 ethnic groups, of which Kinh Vietnamese accounts for $86 \%$ of national population. Kinh along with Chinese (Hoa) are usually classified together as the majority and the remaining 52 smaller ethnic groups are referred to as the minorities. The present study follows the approach taken by Baulch et al. (2007) who classified the minorities into several homogenous categories, following discussion with local anthropologists. They have distinguished 'between three of the main language groups (the Kinh majority, Hoa (Chinese) and Khmer together with a composite category for ethnic minorities with similar livelihood systems that traditionally live in the Central Highlands, and another for those that originate in the Northern Uplands- leading to 4 groups (ibid., 2007, p. 1156). Although they had integrated smaller minority groups, defined as "Other minority" in VLSS, into NU and CH minority groups, we define these as being "Other minority". This is because the households in the "other" category are spread across the country and their geographical living conditions are likely to be very different from the circumstances of Northern Upland and Central Highland regions. The ethnic categorization for the present study is therefore as follows: Majority (Kinh Vietnamese and Chinese) and Minorities (Khmer minority; Norther Upland (NU) minority; Central Highland (CH) minority; Other minority).

The minorities tend to inhabit less productive areas geographically (remote or mountainous areas), with poor access to infrastructures or health and education facilities and to have lower living standards than the majority. Yet their geographic location explains only part of the disparities living standards between two groups (Van de Walle and Gunewardena, 2001; Swinkels and Turk, 2006; Baulch et al., 2007; Baulch, Pham and Reilly, 2008; World Bank, 2008). 
Previous studies attempting to explain the welfare gap between ethnic majority and minorities applied the Blinder-Oaxaca decomposition ${ }^{4}$ which separately identifies the wage gap between two groups into one part due to differences in socio-economic characteristics and another part due to structural differences in the returns to these characteristics (Imai et al, in press). Using 1993 Vietnam Living Standard Survey (VLSS), Van de Walle and Gunewardena (2001) show that there are systematic differences in characteristics and the returns to those characteristics, most of which are in favour of the majority group. Baulch et al. (2007) using VLSS1998 and Imai et al. (in press) using VHLSS 2002 and 2004 show a similar result to Van de Walle and Gunewardena (2001) and confirm that structural component, in general, has became larger. However, none of these studies has explored how economic growth during the second phase of Vietnam's transition towards market economy had differently influenced on the poverty and inequality according to ethnicity ${ }^{5}$.

This study attempts to address three main questions: (1) how the incidences of poverty and inequality have changed during the second phase of economic transition; (2) to what extent any changes in poverty by ethnic group can be explained by variations in economic growth and inequality; and (3) what is the main driver of inequality within each ethnic group. Several analytical tools which were recently developed will be employed to answer these questions. For the last question, the present study will take advantage of regression-based inequality decomposition analyses (e.g. Fields, 2003). To chart the changes over the period since 2002, the study draws upon three rounds of Vietnamese household data covering the transitional period from 2002 to 2006.

\section{Data}

\footnotetext{
${ }^{4}$ The methodology was first developed by Blinder (1973) and Oaxaca (1973).

${ }^{5}$ For the sake of convenience, we distinguish the period of 1993-1998 and 2002-2006 as the first and the second phases of transition respectively.
} 
The present study makes use of the Vietnam Household Living Standard Surveys (VHLSS) 2002, 2004 and 2006. The VHLSSs were designed to collect detailed data on households and communities and were implemented by Vietnam Government Statistical Office (GSO) under donor funding and technical support. They are multi topic household surveys with nationally representative household samples. They commonly cover a wide range of issues, including household composition and characteristics (e.g. education and health), expenditures on food, non-food items, health and education, income by source (e.g. wage and salary, farm or non-farm production), employment and labour force participation, housing, ownership of assets and durable goods. The accompanying commune survey collects information on rural infrastructure and commune characteristics. The total sample size of VHLSS 2002, 2004 and 2006 are 30,000, 9,300 and 9,189 households respectively, with each having similar modules, including income and consumption expenditure data (small sample version). Due to our focus on rural Vietnam as well as missing observations, the present study relies on a final sample size of 22,621 for 2002, 6,737 for 2004 and 5,493 households in 2006 .

\section{Growth, Inequality and Poverty}

\subsection{Incidence of Poverty between 2002 and 2006}

Poverty head count ratio in Vietnam fell from $28.8 \%$ in 2002 to $16.0 \%$ in 2006 (Table 1). Table 1 shows that the urban poverty rate has been stabilised, although it appears to have slightly increased in the most recent survey, as it approaches zero. In contrast, the rural sector has maintained a rapid pace of poverty reduction though the level of reduction has marginally slowed (e.g. 4.18 percentage points in the 1990s, World Bank, 2004), reporting a fall of 3.8 percentage points per year in 2000s. In Vietnam, poverty is largely a rural phenomenon and approximately 13.7 million of people were estimated to be poor in 2006. 


\section{(Table 1 to be inserted around here)}

One notable trend with regard to Vietnam's poverty appears in the ethnic minority data. The annual rate of decline in poverty during the 1990s for these groups was much lower than for their majority counterparts who were the major beneficiaries of economic growth in the initial stages of the transition. However, the pace of poverty reduction for the minority groups surpassed the latter over the period 2002 to 2006 (4.5 vs. 3.9 percentage points per year). Although more than half of the ethnic minority population still lack the resources to satisfy the minimum basic necessities of living standards, this recent rapid decline in poverty among the minority groups might be partly explained by the government's National Targeted Programmes (NTPs). Two of the most successful NTPs are Programme 135 (P135) and the Hunger Eradication and Poverty Reduction programme (HEPR): P135 was established in 1998 aiming to improve the living standards, mainly, of ethnic minority people who lagged behind economic growth; while HERP was established in 1996 to provide the poor (as defined by Ministry of Labour, Invalids and Social Affairs (MOLISA)) with a number of supports including credit, health care and education. ${ }^{6}$ These reductions, however, cannot be attributed solely to these government interventions. Rather, it might be more plausible to argue that while the ethnic majority has been able to adapt itself to a market economy quickly, because of socio-economic as well as geographical advantages, the minorities were incorporated into the market based system only as the transition process has matured.

Table 1 also provides poverty estimates for each of the four disaggregated ethnic minorities, namely, Khmer minority, NU minority, $\mathrm{CH}$ minority and the other minority

\footnotetext{
${ }^{6}$ The second phase of P135 as a five year programme (2006-2010) targets the poorest, the most disadvantaged ethnic minority in 1,644 poor and mountainous communes. It consists of four broad components: 1) Marketoriented agricultural production, 2) Community infrastructure, 3) Capacity building and 4) Improved sociocultural livelihoods.
} 
category. The Khmer are the better-off group among these, recording not only the lowest incidence of poverty in each survey year (34.6\% in 2006) but also the fastest poverty decline, an annual 3.3 percentage points drop, during the period of 2002-2006. The Khmer, are ranked the second following the Thai Vietnamese, and are likely to have enjoyed better economic opportunities than other minority groups since they inhabit in the Mekong Delta and the South East coast while other ethnic minorities live in the more mountainous areas of Vietnam.

\subsection{Pro-Poor Growth}

It is evident that the prominent driver of poverty reduction for both the majority and minorities in rural Vietnam has been long-run economic growth. The question arising is whether, and how much, the gains from economic growth were distributed in favour of the poor? This sub-section examines how economic growth has had differing effects on the living standards of the households according to their ethnicity. One way of investigating this is to provide a summary measure of the rates of pro-poor growth that takes account of the extent to which the poor have benefitted from the economic boom over a certain period. Ravallion and Chen (2003) define the "Growth Incidence Curve" (GIC) which shows how the growth rate for the $p^{\text {th }}$ percentile varies across population ranked by income (or consumption expenditure) and propose a rate of pro-poor growth as the mean growth rate of the poor's income $e^{7}$.

The GIC over the period 1 to 2 can be calculated as follows:

$$
g_{1,2}(p)=\left[\frac{y_{2}(p)}{y_{1}(p)}\right]-1=\frac{\mu_{2} L_{2}^{\prime}(p)}{\mu_{1} L_{1}^{\prime}(p)}-1
$$

\footnotetext{
${ }^{7}$ There are a number of different definitions of pro-poor growth. See Kakwani, Khandker and Son (2004) for the summary of the existing measures of pro-poor growth.
} 
where $y_{t}(p)$ is the income of the $p^{\text {th }}$ percentile at time $t ; \mu_{t}$ and $L_{t}(p)$ represent respectively mean income and the Lorenz curve that shows the cumulative proportion of the population and the cumulative proportion of income $\left(L_{t}^{\prime}(p)\right.$ is the slope of the Lorenz curve).

The rate of pro-poor growth is defined as follows:

$$
\text { Pro-Poor Growth }=\frac{\int_{0}^{H_{1}} g_{1,2}(p) d p}{H_{1}}
$$

where $H_{1}\left(=F_{1}(z)\right)$ is the headcount ratio of poverty at time 1 .

Table 2 provides the estimated rates of the pro-poor growth at the $10^{\text {th }}, 20^{\text {th }}$, and $30^{\text {th }}$ percentiles and for entire population. The first three columns show the growth rates for Vietnam (both urban and rural) and for urban and rural areas. The growth rates for majority and minorities are reported in the fourth and the fifth columns, to be followed by those for each minority group in the last four columns. Figure 1 plots the annual consumption growth rate following the consumption expenditure percentile.

\section{(Table 2 to be inserted around here)}

(Figure 1 to be inserted around here)

The comparison of the per capita expenditure growth rates of the poor groups or the $10^{\text {th }}$, $20^{\text {th }}$, and $30^{\text {th }}$ percentiles and the population average implies the pattern of growth, that is, whether growth has been pro-poor or not in relative sense. The first column indicates that growth was not pro-poor as mean growth rate is higher at the population average than at the $10^{\text {th }}, 20^{\text {th }}$, or $30^{\text {th }}$ percentiles. The poorest group or the $10^{\text {th }}$ percentile benefited least. This corresponds to the first graph in Figure 1 which shows that those between the $30^{\text {th }}$ and the $80^{\text {th }}$ 
percentiles benefited the growth above $6 \%$ in Vietnam. That is, the economic growth during the transition to a market economy was relatively not pro-poor. Rural-urban decomposition in Table 2 shows that the pattern of 'non pro-poor growth' was resulted from the growth pattern in rural areas as the growth was pro-poor in urban areas. A further decomposition in to majority and minorities of rural households in Table 2 suggests that the growth was pro-rich in both groups. In particular, for minorities, the growth rate is higher for the higher percentiles.

The last column of Table 2 presents the disaggregated results for four each minority group. While the poor groups (the $10^{\text {th }}, 20^{\text {th }}$, or $30^{\text {th }}$ percentiles) benefited from high economic growth regardless of their ethnic category in the absolute sense as suggested by positive growth rates of these percentiles for all the sub-groups, the pattern differs considerably across different groups. Economic growth was relatively pro-poor for the Khmer minority. GIC in Figure 1 shows that the poorest $20 \%$ population recoded higher growth rate than the average, whilst a peak is observed above the 80 percentile.

On the other hand, as we have seen in the previous section, ' $\mathrm{CH}$ minority' is the poorest group (in terms of head count ratio), to be followed by 'Other Minority'- around $70 \%$ of households in both groups were still poor in 2006. However, the patterns of growth in consumption expenditure of the two groups are considerably distinct. For example, the relatively poor households in the range of $20^{\text {th }}$ to $40^{\text {th }}$ percentiles in $\mathrm{CH}$ minority benefitted most during the second phase of Vietnam's transition (see Figure 1), while the lowest annual growth in per capita expenditure was $1.64 \%$ at the poorest 10th percentile of the $\mathrm{CH}$ minority as shown in Table 2. That is, there exists the poorest group in the $\mathrm{CH}$ minority which benefited least, while the poor, but not the poorest, benefited most from the economic growth. On the other hand, the NU minority or other ethnic minority experienced highly unequal consumption growth, where the pattern of growth was relatively pro-rich. The fact that the 
speed of poverty reduction of the latter exceeds the former might imply that the higher percentiles groups among the poorer in the NU minority or other ethnic group were just below the poverty threshold and had been able to escape from poverty relatively easily.

\subsection{Change in Inequality}

In this section we examine how the growth process during the transition to a market economy has affected the level of inequality. Taking 1993 as a base year we track the Gini coefficient, which is based on the Lorenz curve and two versions of the Generalised Entropy (GE) measure.

The Gini coefficient is defined as follows:

$$
\text { Gini }=\frac{1}{2 N^{2} \bar{y}} \sum_{i=1}^{N} \sum_{j=1}^{N}\left|y_{i}-y_{j}\right|
$$

where $\bar{y}$ is mean income (or consumption expenditure).

The Gini coefficient ranges from 0 to 1 , representing perfect inequality with 1 . Although the coefficient is a popular measure of inequality, it cannot be easily decomposed as the sum of the Gini coefficients of population sub-groups is not equal to the total Gini coefficient of the population. We need to select the inequality measure based on the criteria for a desirable measure of inequality, such as, income scale independence, principle of population, anonymity, and decomposability. ${ }^{8}$

As an alternative to the Gini coefficient, we also calculate the General Entropy (GE) class of measures. This measure satisfies the desirable properties of the inequality measure, including decomposability. It is defined as:

\footnotetext{
${ }^{8}$ See Litchfield (1999) for the excellent summary of Inequality measure.
} 


$$
G E(\theta)=\frac{1}{\theta(\theta-1)}\left[\frac{1}{N} \sum_{i=1}^{N}\left(\frac{y_{i}}{\bar{y}}\right)^{\theta}-1\right]
$$

where $\theta$ is a discretionary parameter that represents the weight given to distances between incomes at different parts of the income distribution, and can take any real value.

The value of GE measure ranges from zero to infinity, representing higher inequality with higher value. It is more sensitive to changes at the lower (upper) tail of the distribution (i.e. the poorest) for lower (higher) values of $\theta$, and is equally sensitive to changes across the distribution for $\theta$ equal to 1 .

With $\theta=0$, we obtain Theil's L index, often referred to as the Mean Log Deviation:

$$
G E(0)=\frac{1}{N} \sum_{i=1}^{N} \log \frac{\bar{y}}{y_{i}}
$$

With $\theta=1$, we obtain Theil's T index:

$$
G E(1)=\frac{1}{N} \sum_{i=1}^{N} \frac{y_{i}}{\bar{y}} \log \frac{y_{i}}{\bar{y}}
$$

Table 3 reveals that rural Vietnam has shown, using both measures, a moderate increase in inequality in per capita consumption expenditure between 2002 and 2006.

\section{(Table 3 to be inserted around here)}

In particular, the higher rate of increase given by $\mathrm{GE}(0)$ than $\mathrm{GE}(1)(18.0 \%$ vs. $15.4 \%)$ implies that the distribution of consumption expenditure per capita became more unfavourable at the lower part of the distribution (i.e. for the poor). Furthermore, in contrast to the majority group where the change in inequality is moderate though the level of inequality is high, the inequality within the ethnic minorities increased during 2002 and 2006. 
It was noted in the earlier section that one reason for the recent decline in poverty ratio of minority groups could be their progressive integration into the new economic system. We might interpret the relatively worsening of "within" inequality in ethnic minorities as the consequences of different socio-economic behaviours of different ethnic origins. Among 52 minorities, certain ethnic minority groups still retain their own culture, economic behaviour and their own language whereas other groups are relatively homogeneous and assimilated with the Kinh majority including the Chinese Vietnamese. It is thus possible that the latter enjoyed better economic opportunities to enable them to benefit from the transition process than did the former, by following the majority group which had already incorporated themselves into the new economic system in earlier stages of the transition. The arguments put forward by Baulch et al. (2007) follow this line - that "There are, therefore, at least two paths to prosperity for the ethnic minorities. One path is to assimilate, both economically and culturally, with the majority group.... A second path, pursued by such groups as the Khmer and Thai, is to integrate economically with the Kinh while retaining their own group's cultural identity.” (Baulch et al. 2007, p.1174)

\subsection{Decomposition of Changes in Poverty}

The change of poverty can be decomposed into two effects: one resulting from the change in mean income or consumption expenditure (found by isolating the change while holding the distribution of wealth among population constant); and a distribution effect (found by holding mean income constant). It is, for example, possible that poverty could decline without any economic growth in a given period, so long as redistribution took place towards the poor. Hence, we now investigate the relative contributions of growth and the redistribution 
components to the poverty changes. This provides useful insights for understanding the impact of economic growth in rural Vietnam and its effect on the poor.

There are several frameworks that offer a means of decomposing changes in poverty into growth and redistribution components. Datt and Ravallion (1992) devised a method with the initial period as a reference anchor point which decomposes the change of poverty into growth, redistribution and residual components. This would naturally prompt questions on interpretation of the residual term, being the difference between the growth (redistribution) components evaluated at the terminal and initial Lorenz curves (mean incomes) respectively. Another limitation is the asymmetric treatment of the initial and terminal periods by using a benchmark period.

To overcome these limitations, Kakwani (2000) developed an alternative formulation using an axiomatic approach in which the residual term is averaged between the other components. Another alternative is a Shapley-valued based decomposition, proposed by Shorrocks (1999). Although these alternative methods adopt different terminologies in decomposing poverty change into the effects of growth and redistribution components, they produce essentially the same results, and suggest the exact decomposition and symmetry factors. The idea underlying all of these alternatives is computing the effect of each component by taking an average of the corresponding components based on the initial and the terminal year (Duclos and Araar, 2006). Formally:

$$
\begin{aligned}
& \Delta P=P_{1}-P_{0}=G+D \\
& G=\frac{1}{2}\left[P\left(\frac{z}{\mu_{1}}, L_{0}\right)-P\left(\frac{z}{\mu_{0}}, L_{0}\right)\right]+\frac{1}{2}\left[P\left(\frac{z}{\mu_{1}}, L_{1}\right)-P\left(\frac{z}{\mu_{0}}, L_{1}\right)\right]
\end{aligned}
$$




$$
D=\frac{1}{2}\left[P\left(\frac{z}{\mu_{0}}, L_{1}\right)-P\left(\frac{z}{\mu_{0}}, L_{0}\right)\right]+\frac{1}{2}\left[P\left(\frac{z}{\mu_{1}}, L_{1}\right)-P\left(\frac{z}{\mu_{1}}, L_{0}\right)\right]
$$

where $\mathrm{G}$ and $\mathrm{D}$ represent the growth and redistribution effects respectively; $\mathrm{z}$ is the poverty line; $\mu_{t}$ is the mean income at period; $L_{t}$ is the Lorenz curve representing the structure of relative income inequalities at each period ${ }^{9}$.

Our decomposition of poverty changes is reported in Table 4 and illustrated in Figure $2^{10}$. It is clear that poverty reduction in Vietnam's case has largely been determined by increases in consumption expenditure as a proxy of households' welfare.

\section{(Table 4 to be inserted around here)}

\section{(Figure 2 to be inserted around here)}

The positive sign on the redistribution component indicates a negative impact on poverty reduction due to worsened inequality. Hence, the national poverty would have declined further as a result of economic growth if inequality had not changed - i.e. a realised decline of -0.119 versus a potential of -0.123 (as given by the growth component during 2002-2006). Rural-urban decomposition shows the same pattern, that is, poverty reduction was solely as a result of growth, not redistribution. Redistribution effect was poverty increasing in both urban and rural areas. Reduction of poverty head count ratio in terms of percentage was smaller in urban areas because the ratio in 2002 was as low as $6.5 \%$ (see Table 1).

\footnotetext{
${ }^{9}$ The poverty measure is homogenous of degree zero in $\mu_{t}$, and $\mathrm{z}$, meaning that poverty will remain unchanged if both indicators change by the same portion. If an expected function of the Lorenz curve is chosen from either Beta or General Quadratic (GQ) forms, one can calculate the poverty measures (the head count index, the poverty gap index, and the squared poverty gap index) using the fomulas in Datt (1998). See Datt (1998) for more details of computational tools for poverty measure.

${ }^{10}$ For poverty decomposition, the present study uses Distributive Analysis Stata Package (DASP). See Araar and Duclos (2007).
} 
The redistribution component continued to offset the growth impact in each period for ethnic majority, the redistribution reduced poverty for minorities in the second phase of economic transition. For example, poverty reduction within minority groups driven by redistribution in 2004-2006 was reasonably large (-0.017). At disaggregated level, the decomposition results for the Khmer minority shows that the group benefited from an exceptionally high economic growth effect on poverty reduction during 2002-2004, but suffered from an offsetting substantial inequality. The realised poverty decline was 0.153 , while a potential decline of 0.237 would have been achieved only by growth with income distribution unchanged. However, during the 2004-2006 period, a relatively large contribution was observed from the redistribution effect. These results suggest that the decline in poverty in the same period resulted predominantly from the change in distribution. For the NU minority, the contribution of redistribution supplemented the impact of growth on poverty reduction ${ }^{11}$. On the other hand, the pattern observed from the $\mathrm{CH}$ minority is opposite to that of Khmer. While the redistribution component was negative and thus reduced poverty in 2002-4, it became positive in 2004-6 to offset a part of the poverty-reducing effect of growth.

We have seen not only how poverty and inequality have evolved over the period 20022006, but also how growth and redistribution affected poverty of each ethnic group. In particular, the summary measures of inequality decomposition suggest that inequality is dominated by 'within group' inequality. The next section will be devoted to the regression based decomposition of inequality within each ethnic group to shed some empirical light on the main factors underlying 'within group' inequality.

\footnotetext{
${ }^{11}$ Note that the negative redistribution component here for NU minority does not mean that the redistribution was in favour of all the poor. It simply means that a part of the poverty reduction was due to redistribution. As we have seen in the earlier section, economic growth of NU minority was pro-rich during 2002-2006 in a relative sense. If we consider this, it is more reasonable to interpret the result of the redistribution component in poverty decompostion such that although economic growth resulted in the worsened inequality within NU minority, the redistribution was taken place in the direction to lift the marginally poor households in NU minority group out of poverty.
} 


\section{Regression Based Decomposition of Inequality}

In the earlier sections, we have observed that the nature of economic growth is diverse across different ethnic minority groups- the growth was either pro-poor or pro-rich for different groups. It has been also observed that the redistribution component has a different effect on each of 5 ethnic groups. These summary measures might reflect different socioeconomic characteristics of each ethnic minority groups rooted in their own culture or the geographical location that would make them react differently to rapid changes in the transition period. The figures also suggest that there is a considerable heterogeneity in reacting to the rapid transition within each ethnic group- some households benefited from the transition or the economic growth, while some, for example, the poorest, for example, the poorest of the $\mathrm{CH}$ minority, did not. Nevertheless, the existing literature on inequality in Vietnam has mainly focused on 'between groups' inequality, that is the welfare gap between the ethnic majority and minority groups (Van de Walle and Gunewardena, 2001; Baulch et al., 2007; Imai et al., in press) drawing upon the Blinder-Oaxaca decomposition technique proposed by Blinder (1973) and Oaxaca (1973). Given the heterogeneity of household characteristics within each ethnic group, however, analysing the sources of inequality within each group might also offer an important insight into rising inequality as shown in Table 2 and Figure 1.

In order to identify how much of inequality can be attributed to each explanatory factor, we apply the regression-based decomposition method proposed by Fields (2003). This technique enables us to quantify the sources of inequality and to clarify how the main force of inequality differs across 5 ethnic groups.

We first estimate the following log per capita consumption expenditure of $i^{\text {th }}$ household in $j^{\text {th }}$ ethnic group at time $t$. 


$$
\ln c_{i j t}=\alpha_{j t}+X_{i j t} \beta_{j t}+\varepsilon_{i j t} \quad i=1, \ldots, \mathrm{N}, j=1, \ldots, 5
$$

A vector of household characteristics $\left(X_{i j t}\right)$ includes various household and commune characteristics: the age of a household head and its square, gender of the head of household, their marital status, the share of female members, the dependency burden, the highest educational attainment of household members, the ratio of household members working in the industrial sector, the sizes of agricultural, sylvicultural, and aquacultural lands. We also include a dummy variable for whether a household receives remittances and dummy variables describing whether a household resides in a temporary as a base, semi-permanent or permanent dwelling ${ }^{12}$.

Taking covariance with total consumption expenditure, $\ln c$, allows us to compute the factor contribution of log variance of per capita consumption expenditure as follows:

$$
s_{j}(\ln c)=\frac{\operatorname{cov}\left(\beta_{j} X_{j}, \ln c\right)}{\sigma^{2}(\ln c)}=\frac{\beta_{j}^{*} \sigma\left(X_{j}\right) * \operatorname{cor}\left(X_{j}, \ln c\right)}{\sigma(\ln c)}
$$

Closely related to the way proposed by Shorrocks (1982), this decomposition methodology can be applied to a broad class of inequality measures that is continuous, symmetric and equal to zero when all consumption expenditure are equal among households (Fields, 2003).

The results of regressions on the determinants of rural household's per capita consumption expenditure generally show similar patterns across the defined ethnic groups. For example, having more educated household members, working in industry, and owning

\footnotetext{
${ }^{12}$ The list of the variables, definitions and population mean values are given in Appendix B.
} 
land tend to increase households' consumption level while a higher dependency burden and a larger share of female members are likely to negatively affect households' living standards. ${ }^{13}$

The results of decomposition are given by Table 5 where we observe different patterns in sources of inequality. ${ }^{14,15}$

\section{(Table 5 to be inserted around here)}

As shown in the upper panel of Table 5, in 2002 the contribution of household demographic on total inequality is not relatively large across different ethnic groups -in particular for minority groups- over the years. The factor of educational attainment accounts for $30 \%-50 \%$ of inequality for majority, Khmer minority and NU minority groups. In contrast, the contribution of education is very small for $\mathrm{CH}$ minority and other minority groups. It is worthwhile to note that the estimates of factor contribution of inequality should not be misinterpreted to derive any policy implications. For example, compared to inequality attributable to asset factor in $\mathrm{CH}$ minority in 2002 (55\%), lower contribution of education to total inequality (3.65\%) is likely to draw our less attention to the importance of the provision of educational facilities. However, this low contribution found in $\mathrm{CH}$ minority may simply reflect lower educational attainment across most of the households in the group which resulted in lower inequality of education. Hence, the provision of schools and improving access to those facilities would be necessary for reducing absolute poverty of $\mathrm{CH}$ minority group.

\footnotetext{
${ }^{13}$ The tables for the regression results are omitted for the sake of brevity. They will be furnished on request.

${ }^{14}$ We decompose inequality of the predicted per capita consumption expenditure instead of per consumption expenditure itself in order to avoid having the residuals contributing as an unexplained part of inequality. The proportional contributions of factors found by decomposing the predicted value is essentially equivalent to the shares of the factor contributions when decomposing actual per capita consumption and taking the explained part of inequality as total inequality.

${ }^{15}$ As the proportional contributions of the independent variables are additive and sum to 1 (or $100 \%$ ), we group these contributions into 4 categories - Household demographic, Education, Asset and Infrastructure. The results of disaggregated levels are given in Appendix.
} 
In contrast, an attempt to reallocate asset factor (e.g. land holding) might operate directly on total inequality (as relative poverty). It is also found that asset factor is closely associated with household consumption inequality for Khmer and $\mathrm{CH}$ minority. In particular, $55 \%$ of inequality within $\mathrm{CH}$ group stems from difference in asset holdings. Ravallion and Van de Walle (2006) found the supporting evidence of successful land reforms in Vietnam which resulted in efficient re-allocation during the process of transition. However, their finding may not be applicable to the $\mathrm{CH}$ minority group. The substantial impact of asset factor on inequality implies that a further government's intervention leading to more drastic land reallocation is necessary for an effective pro-poor policy for $\mathrm{CH}$ minority. While infrastructure has little impact on inequality within the majority, it shows a relatively large association with inequality within each of minority groups, especially for 'other minority'.

The findings in 2002 broadly hold in 2004 and 2006. For example, the main driver of inequality within each group was generally unchanged. A few additional key findings are worth mentioning here. First, infrastructure was negligible over time in accounting for inequality of majority. Second, it is surprising to find that $60 \%$ to $70 \%$ of inequality in Khmer minority in 2004 and 2006 is attributed to the asset factor. We also observe the significant decline in the contribution of education factor for Khmer minority. Third, while the importance of assets in accounting for inequality within $\mathrm{CH}$ minority has decreased, especially in 2006, the contribution of infrastructure increased during four years. However, those two factors - assets and infrastructure factors - still dominate other factors. Finally, other minority group shows most dramatic changes. For example, educational attainment explains only $7 \%$ and $3.5 \%$ of total inequality in 2002 and 2004 respectively. However, the contribution of education to inequality has been sharply increased as to accounting for $32 \%$ of inequality. Infrastructure factor was consistently one of the most important factors. 
Our analysis on sources of inequality shows ethnic minorities in Vietnam should not be explained by a single category - ethnic minority. Nonetheless, as we stated earlier, the studies on ethnicity in Vietnam have been mainly focused on the welfare gap between ethnic majority and minority, in which an important sight may be lost on diversity among ethnic minorities. For majority, consumption inequality was mostly associated with education, to be followed by household characteristics and asset and the unequal access to infrastructure was not a main factor for inequality. Thus, guaranteeing education access for all the households would be a key for inequality reduction. For Khmer minority, asset inequality was the main driver of inequality, while equal access to infrastructure would be important. For NU minority, inequality of educational attainment was a main driver of inequality, to be followed by asset and infrastructure. For $\mathrm{CH}$ minority and other minority, asset or infrastructure was the most important. Our decomposition analysis of inequality supports that understanding the diversity of causes for inequality across different ethnic groups would be needed for designing public policy to reduce inequality and to increase the living standards of Vietnamese households. Given the diversity across different ethnic groups, if our analysis has some validity for policy discussions, we can conclude that the governmental policy aiming at equal access to infrastructure and more equal distribution of assets, such as land, for ethnic minority groups would lead to more equal distribution of consumption and poverty reduction of those groups.

\section{Conclusions}

In the present study, we have examined the changes of poverty, inequality and growth in rural Vietnam and the role played by ethnicity, during Vietnam's post transition economic expansion. Specifically, we have attempted to explain different achievements among 5 representative ethnic groups. It is clear from the latest poverty data that although half of the 
minority population still fails to meet the basic needs for their life, the pace of annual poverty reduction for these groups has surpassed that of majority group over the period 2002 to 2006 . This implies that Vietnam's growth benefited majority first, and then promoted the improvement of living standards of minority groups. Economic growth during the transition period has generally been, in a relative sense, non-pro-poor. The estimated growth rate by ethnic sub-group, however, suggests that more detailed investigation into the livelihoods of each ethnic society is required as the growth has different effects depending on the household location in distribution of consumption expenditure and on ethnic category to which a household belongs. For example, even among the ethnic minorities, the characteristics of economic growth differ substantially (notably between the NU minority versus. the $\mathrm{CH}$ minority).

For the poverty decomposition, we have seen that redistribution has contributed to poverty reduction of households in NU minority and other ethnic minority groups, whereas inequality within the majority, Khmer minority and $\mathrm{CH}$ minority groups continued to offset the growth impact over time. It is evident from our summary measures that the minorities in rural Vietnam are very heterogeneous and have been differently influenced by Vietnam's transition (i.e. the patterns of contributions of growth and inequality vary considerably according to ethnicity).

Our analysis quantifying the sources of inequality also provides us with similar conclusions. The factors contributing to consumption inequality within each ethnic group varied considerably depending on the ethnic category and they were mostly consistent over time. Moreover, while a factor had a small effect on inequality of some ethnic groups, it had a dominant effect on other ethnic groups (e.g. asset for Khmer minority). These findings suggest that a uniform government intervention to prevent inequality from rising with focus 
on only one factor, such as education, is likely to have a different effect on inequality of a different ethnic group. However, given the diversity across different ethnic groups, we can conclude that the governmental policy aiming at equal access to infrastructure and more equal distribution of assets, such as land, for ethnic minority groups would lead to more equal distribution of consumption and poverty reduction of those groups. Also, consideration of local needs of each ethnic minority group would be necessary in designing and implementing public policies given the heterogeneous socio-economic circumstances surrounding each ethnic minority group. This can be delivered by more precise investigation of ethnic minorities at disaggregate level and one suggested disaggregation here is to take account of different geographical environment as it is one of the key factors for heterogeneity of ethnic minorities. 


\section{References}

Araar, A., \& Duclos, J-Y. (2007). User Manual DASP version 1.4, DASP: Distributive Analysis Stata Package.

Baulch, B., Chuyen, T.T.K., Haughton, D.H., \& Haughton, J. (2007). Ethnic Minority Development in Vietnam. Journal of Development Studies, 43(7), 1151-1176.

Baulch, B., Pham, H. T., \& Reilly, B. (2008). Ethnicity and Household Welfare in Rural Vietnam, 1993 - 2004. A Draft. Institute of Development Studies, University of Sussex.

Chaudhuri, S., Jalan, J., \& Suryahadi, A. (2002). Assessing Household Vulnerability to Poverty from Cross-Sectional Data: A Methodology and Estimates from Indonesia. Discussion Paper, Columbia University.

Datt, G. (1998). Computational Tools for Poverty Measurement and Analysis. FCND Discussion Paper No.50. International Food Policy Research Institute.

Datt, G., \& Ravallion, M. (1992). Growth and Redistribution Components of Changes in Poverty Measures: A Decomposition with Applications to Brazil and India in the 1980s. Journal of Development Economics, 38, 275-295.

Dollar, D., \& Litvack, J. (1998). Macroeconomic Reform and Poverty Reduction in Vietnam. In D. Dollar, P. Glewwe, \& J. Litvack (Eds.), Household Welfare and Vietnam's Transition. Washington, D.C: The World Bank.

Duclos, J-Y., \& Araar, A. (2006). Poverty and Equity: Measurement, Policy, and Estimation with $D A D$. New York: Springer and Otawa: the International Development Research Centre.

Evans, M., \& Harkness, S. (2008). Social Protection in Vietnam and Obstacles to Progressivity. Asian Social Work and Policy Review, 2, 30-52.

Fields, G. (2003). Accounting for Income Inequality and Its Change: A New Method, with Application to the Distribution of Earnings in the United States. In S. W. Polachek (Ed.), Research in Labor Economics, 22, JAI Press Inc.

Imai, K., Gaiha, R., \& Kang, W. (in press). Poverty, Inequality and Ethnic Minorities in Vietnam. International Review of Applied Economics.

Jain, L.R., \& Tendulkar, S.D. (1990). The Role of Growth and Distribution in the Observed Change in Head-Count Ratio-Measure of Poverty: A Decomposition Exercise for India. Indian Economic Review, Vol.XXV No.2, 165-205

Kakwani, N. (2000). On Measuring Growth and Inequality Components of Poverty with Applications to Thailand. Journal of Quantitative Economics, 16, 67-80

Kakwani, N., Khandker, S., \& Son, H. (2004). Pro-Poor Growth: Concepts and Measurement with Country Case Studies. International Poverty Centre Working Paper No.1, UNDP 
Klump, R. (2007). Pro-Poor Growth in Vietnam: Miracle or Model?. In T. Besley, \& L. J. Cord (Eds.), Delivering On the Promise of Pro-Poor Growth: Insights and Lessons from Country Experiences. Washington, D.C.: The World Bank and Basingstoke: Palgrave Macmillan.

Litchfield, J. (1999). Inequality: Methods and Tools. The World Bank. (mimeo).

Pincus, J., \& Sender, J. (2008). Quantifying Poverty in Viet Nam: Who Counts?. Journal of Vietnamese Studies, 3(1), 108-150

Raballion, M., \& Chen, S. (2003). Measuring Pro-Poor Growth. Economic Letters, 78(1), 9399.

Ravallion, M., \& Van de Walle, D. (2006). Land Reallocations in an Agrarian Transition. The Economic Journal, 116, 924-942

Shorrocks, A. (1982). Inequality Decomposition by Factor Components. Econometrica, 50, 193-212.

Shorrocks, A. (1999). Decomposition Procedures for Distributional Analysis: A Unified Framework Based on Shapley Value, Department of Economics, University of Essex. (mimeo).

Swinkels, R., \& Turk, C. (2006). Explaining Ethnic Minority Poverty in Vietnam: a summary of recent trends and current challenges. (mimeo)

Van de Walle, D., \& Gunewardena, D. (2001). Sources of ethnic inequality in Viet Nam. Journal of Development Economics, 65(1), 177-207

World Bank (2004). Vietnam Development Report 2004: Poverty. Hanoi: World Bank. Bank.

(2008). Vietnam Development Report 2008: Social Protection. Hanoi: World 
Table 1 Change in Poverty Head Count Ratio during 2002-2006

\begin{tabular}{lcccc}
\hline Poverty head count ratio & 2002 & 2004 & $2006^{*}$ & $\begin{array}{c}\text { Annual \% point change } \\
(2002-2006)\end{array}$ \\
\hline Vietnam & 28.8 & 19.5 & 16.0 & -3.2 \\
Urban & 6.5 & 3.6 & 3.9 & -0.7 \\
Rural & 35.5 & 25.0 & 20.4 & -3.8 \\
& & & & -3.9 \\
Majority & & Rural & 13.5 & -4.5 \\
Minorities & 29.0 & 17.8 & 54 & -5.5 \\
& 72.1 & 62.7 & & -4.7 \\
Khmer minority & & & 34.6 & -3.9 \\
NU minority & 56.5 & 41.3 & 50.9 & -4.5 \\
CH minority & 69.6 & 61.0 & 71.5 & 69.3 \\
Other minority & 87.0 & 76.1 & 77 & \\
\hline Source: Authors & 87.4 & & & \\
\hline
\end{tabular}

Source: Authors' calculation

* The estimates for 2006 were based on the poverty line, 2,455 thousands VND, that deflated from 2004 poverty line using annual Consumer Price Index (CPI) over the periods. These estimates are slightly lower than World Bank's unofficial poverty ratio for 2006. For example, national, urban and rural poverty rates were estimated at $16.0 \%, 3.9 \%$ and $20.4 \%$ respectively. (See Vietnam Development Report 2008)

Table 2 Rates of Pro-Poor Growth in Rural Vietnam during 2002-2006

\begin{tabular}{|c|c|c|c|c|c|c|c|c|c|}
\hline Percentile & Vietnam & Urban & Rural & Majority & Minorities & $\begin{array}{l}\text { Khmer } \\
\text { Minority }\end{array}$ & $\begin{array}{c}\text { Northern } \\
\text { Upland } \\
\text { Minority }\end{array}$ & $\begin{array}{c}\text { Central } \\
\text { Highland } \\
\text { Minority }\end{array}$ & $\begin{array}{c}\text { Other } \\
\text { Minority }\end{array}$ \\
\hline 10 & 4.10 & 3.65 & 3.75 & 5.09 & 2.25 & 6.43 & 1.85 & 1.64 & 3.78 \\
\hline 20 & 4.79 & 4.53 & 4.42 & 5.71 & 3.19 & 6.06 & 2.74 & 4.32 & 3.16 \\
\hline 30 & 5.23 & 4.86 & 4.90 & 6.04 & 3.68 & 5.40 & 3.19 & 5.61 & 3.30 \\
\hline $\begin{array}{l}\text { Mean growth rate } \\
\text { - entire population }\end{array}$ & 6.19 & 4.22 & 6.38 & 6.99 & 5.10 & 4.85 & 5.07 & 6.40 & 6.05 \\
\hline
\end{tabular}

Source: Authors' calculation

Table 3 Inequality Measures in Rural Vietnam during 2002 - 2006

\begin{tabular}{lccc|c}
\hline & 2002 & 2004 & 2006 & $\begin{array}{c}2002-2006 \\
(\% \text { change })\end{array}$ \\
\hline Gini coefficient & 0.281 & 0.295 & 0.302 & 7.5 \\
GE(0) - Theil's L & 0.128 & 0.143 & 0.151 & 18.0 \\
GE(1) - Theil's T & 0.136 & 0.15 & 0.157 & 15.4 \\
& & & & 6.0 \\
Within Ethnic majority/minorities & & & 0.284 & 8.2 \\
Gini within majority & 0.268 & 0.277 & 0.276 & 13.9 \\
Gini within minorities & 0.255 & 0.282 & 0.131 & 18.1 \\
GE(0) within majority & 0.115 & 0.125 & 0.124 & \\
GE(0) within minorities & 0.105 & 0.128 & & \\
\hline Source: Authors calcut
\end{tabular}

Source: Authors' calculation 
Table 4 Poverty Decomposition into Growth and Inequality during 1993-2006

\begin{tabular}{|c|c|c|c|c|}
\hline & & $2002-2004$ & $2004-2006$ & $2002-2006$ \\
\hline \multirow{3}{*}{ Vietnam } & Poverty Change & -0.093 & -0.035 & -0.119 \\
\hline & Growth Component & -0.099 & -0.028 & -0.123 \\
\hline & Redistribution Component & 0.006 & -0.007 & 0.004 \\
\hline \multirow[t]{3}{*}{ Urban } & Poverty Change & -0.030 & 0.003 & -0.020 \\
\hline & Growth Component & -0.020 & 0.001 & -0.027 \\
\hline & Redistribution Component & -0.010 & 0.002 & 0.007 \\
\hline \multirow[t]{3}{*}{ Rural } & Poverty Change & -0.105 & -0.046 & -0.142 \\
\hline & Growth Component & -0.119 & -0.059 & -0.155 \\
\hline & Redistribution Component & 0.014 & 0.013 & 0.013 \\
\hline \multirow[t]{3}{*}{ Majority } & Poverty Change & -0.111 & -0.044 & -0.143 \\
\hline & Growth Component & -0.125 & -0.058 & -0.153 \\
\hline & Redistribution Component & 0.014 & 0.014 & 0.010 \\
\hline \multirow[t]{3}{*}{ Minorities } & Poverty Change & -0.094 & -0.087 & -0.150 \\
\hline & Growth Component & -0.094 & -0.070 & -0.142 \\
\hline & Redistribution Component & 0 & -0.017 & -0.008 \\
\hline \multirow{3}{*}{$\begin{array}{l}\text { Khmer } \\
\text { minority }\end{array}$} & Poverty Change & -0.153 & -0.067 & -0.115 \\
\hline & Growth Component & -0.237 & 0.023 & -0.132 \\
\hline & Redistribution Component & 0.084 & -0.090 & 0.017 \\
\hline \multirow[t]{3}{*}{ NU minority } & Poverty Change & -0.086 & -0.101 & -0.165 \\
\hline & Growth Component & -0.066 & -0.094 & -0.152 \\
\hline & Redistribution Component & -0.020 & -0.007 & -0.013 \\
\hline \multirow[t]{3}{*}{$\mathrm{CH}$ minority } & Poverty Change & -0.108 & -0.046 & -0.137 \\
\hline & Growth Component & -0.080 & -0.095 & -0.158 \\
\hline & Redistribution Component & -0.029 & 0.049 & 0.020 \\
\hline \multirow[t]{3}{*}{ Other minority } & Poverty Change & -0.104 & -0.077 & -0.152 \\
\hline & Growth Component & -0.137 & 0.001 & -0.140 \\
\hline & Redistribution Component & 0.033 & -0.078 & -0.012 \\
\hline
\end{tabular}

Source: Authors' calculation 
Table 5 Regression Based Inequality Decomposition within Ethnic Group in 2002, 2004 and 2006

\begin{tabular}{|c|c|c|c|c|c|}
\hline 2002 & Majority & Khmer minority & NU minority & CH minority & Other minority \\
\hline Household & 25.87 & 7.79 & 8.24 & 12.79 & 6.88 \\
\hline Education & 41.28 & 28.74 & 49.65 & 3.65 & 6.90 \\
\hline Asset & 23.04 & 39.17 & 24.22 & 55.12 & 38.10 \\
\hline Infrastructure & 9.82 & 24.30 & 17.89 & 28.44 & 48.12 \\
\hline SUM & 100 & 100 & 100 & 100 & 100 \\
\hline \multicolumn{6}{|l|}{2004} \\
\hline Household & 12.09 & 4.16 & 2.02 & 13.69 & 7.43 \\
\hline Education & 58.68 & 9.46 & 61.38 & 8.84 & 3.74 \\
\hline Asset & 26.07 & 71.36 & 19.21 & 39.88 & 53.96 \\
\hline Infrastructure & 3.17 & 15.01 & 17.40 & 37.59 & 34.86 \\
\hline SUM & 100 & 100 & 100 & 100 & 100 \\
\hline \multicolumn{6}{|l|}{2006} \\
\hline Household & 22.44 & 5.97 & 15.44 & 24.63 & 8.61 \\
\hline Education & 41.01 & 7.39 & 44.61 & 9.80 & 32.21 \\
\hline Asset & 32.48 & 63.53 & 21.97 & 23.07 & 21.52 \\
\hline Infrastructure & 4.07 & 23.11 & 17.99 & 42.50 & 37.66 \\
\hline SUM & 100 & 100 & 100 & 100 & 100 \\
\hline
\end{tabular}

Source: Authors' calculation 
Figure1. Growth Incidence Curve (GIC) in 2002 - 2006

\section{Vietnam}

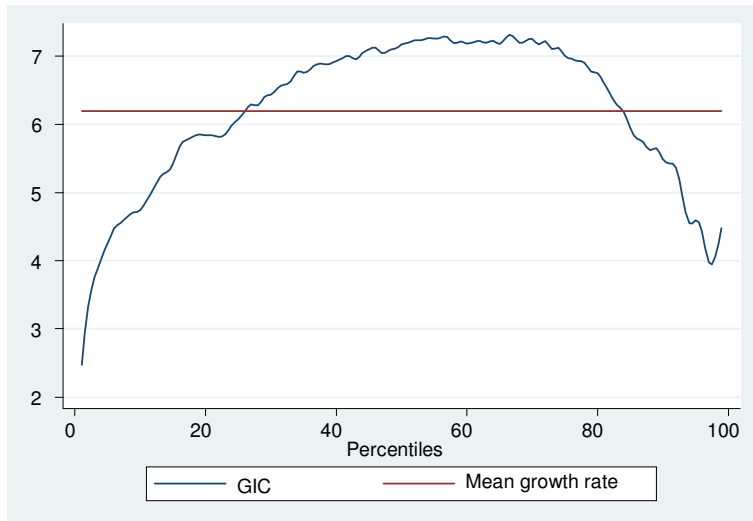

\section{Urban}

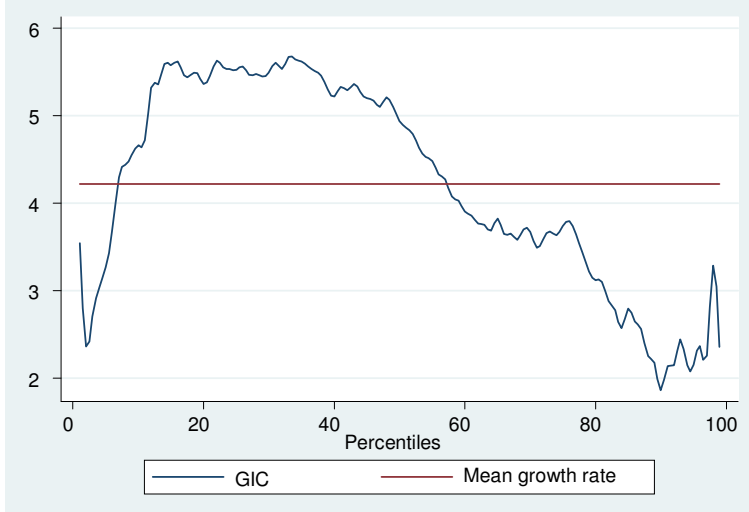

\section{Rural}

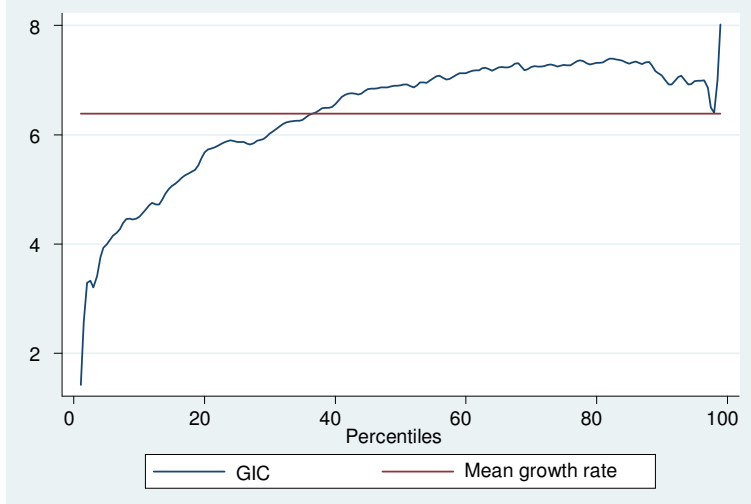

\section{Majority}

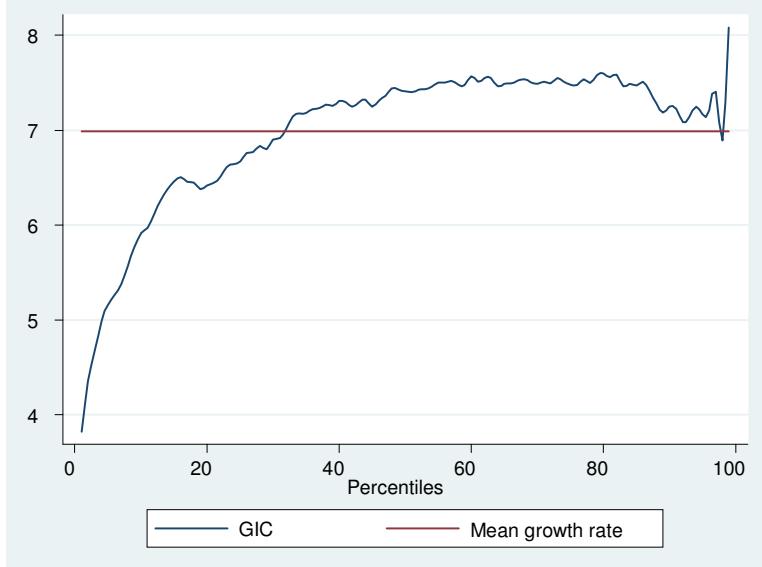

\section{Khmer minority}

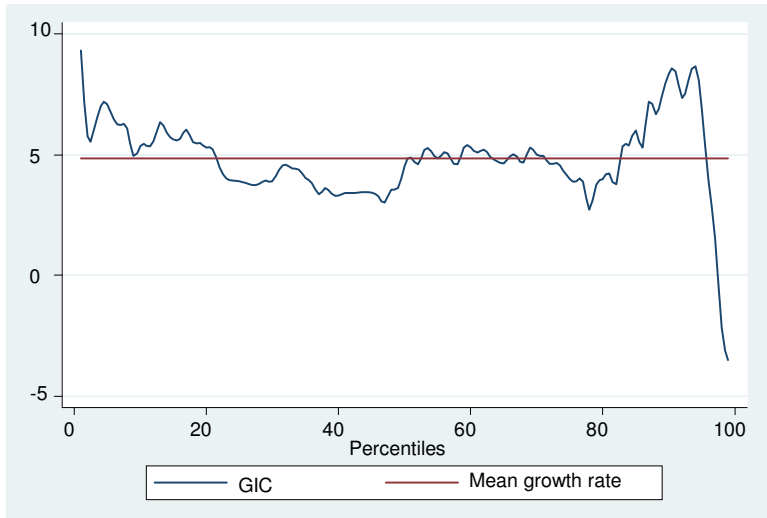

\section{NU minority}

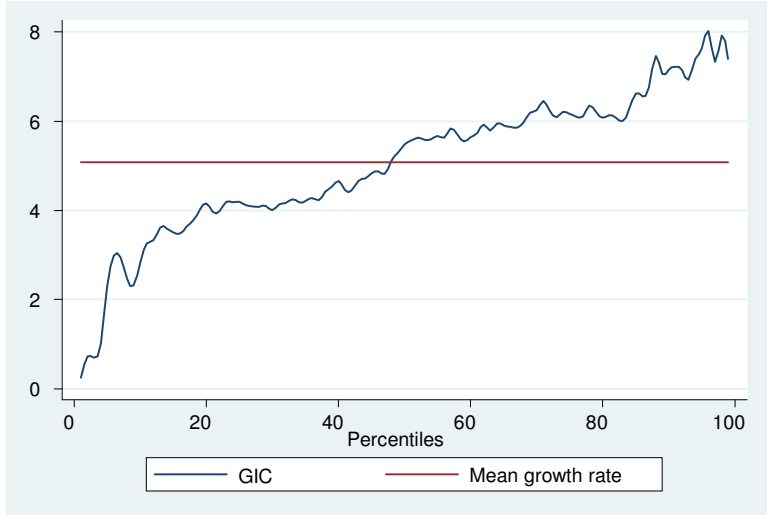

\section{CH minority}

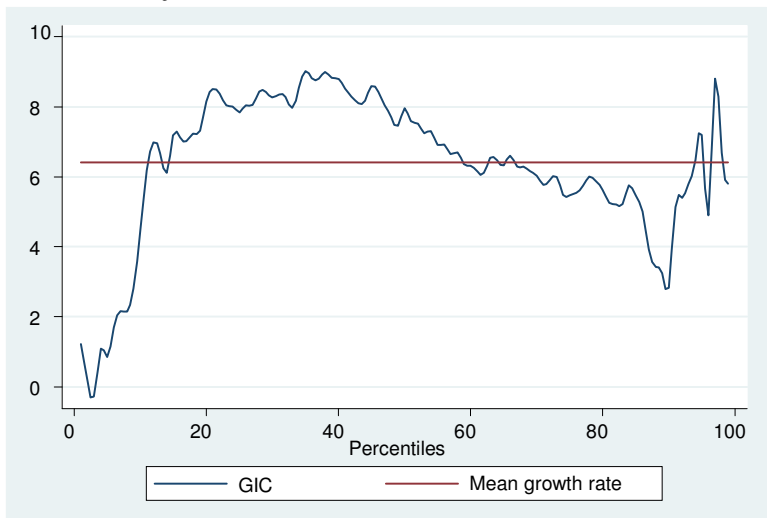

\section{Other minority}

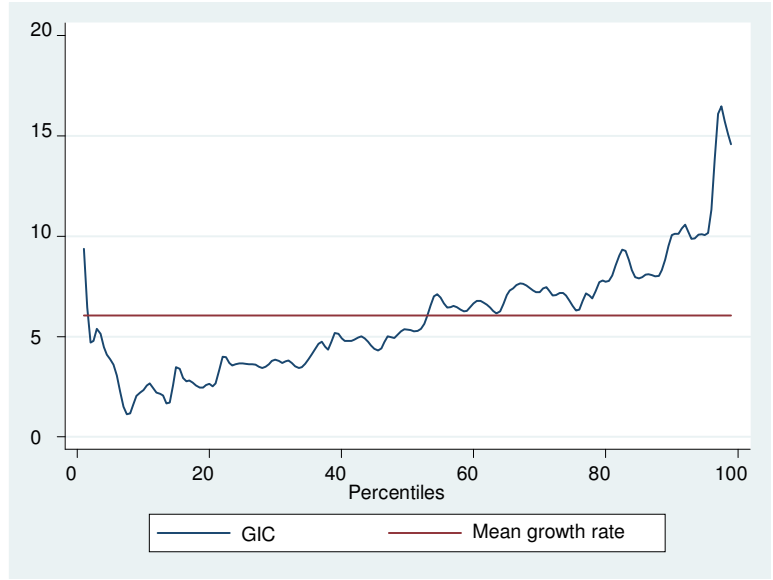


Figure2. Poverty Decomposition into Growth and Redistribution Components
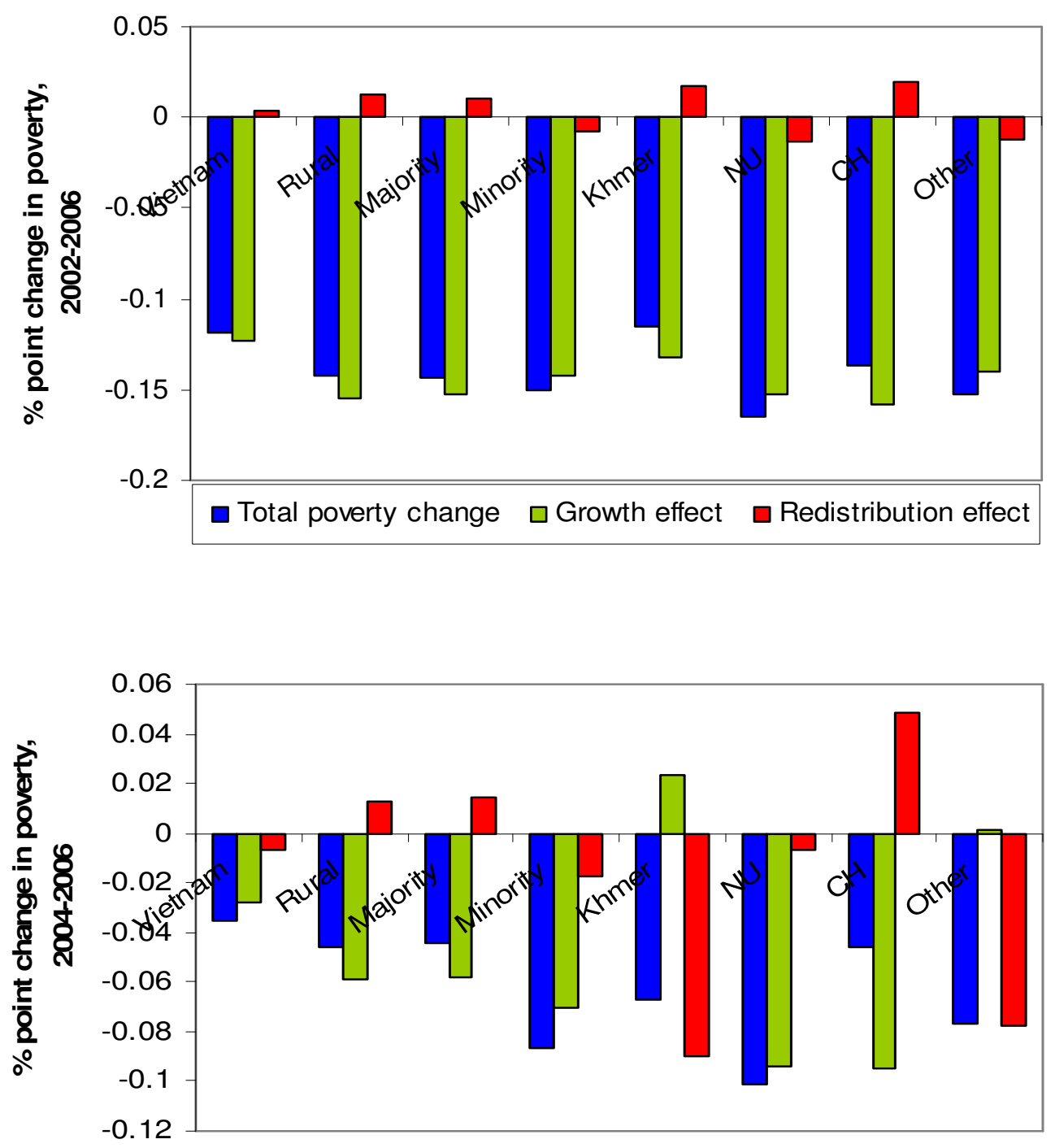
Appendix A.

Proportion of factor contribution to total inequality in $\mathbf{2 0 0 2}$

\begin{tabular}{|c|c|c|c|c|c|}
\hline & Majority & Khmer minority & NU minority & CH minority & Other minority \\
\hline Age of household head & -18.74 & -2.91 & -10.22 & -9.27 & -7.54 \\
\hline (Head age) 2 & 16.46 & 3.80 & 6.76 & 9.40 & 6.43 \\
\hline Female headship & 1.77 & 0.10 & 0.75 & -0.38 & 0.57 \\
\hline Married & -0.10 & 0.00 & 0.26 & 1.25 & -0.65 \\
\hline Share of female members & 3.94 & 1.05 & 3.19 & -1.37 & -2.82 \\
\hline (Female share) 2 & -3.17 & -0.15 & -2.08 & 2.00 & 5.14 \\
\hline Dependency burden & 25.70 & 5.90 & 9.59 & 11.17 & 5.76 \\
\hline Primary education & 1.34 & -0.31 & -4.66 & -0.15 & 2.08 \\
\hline Secondary education & -0.13 & 16.74 & 15.80 & 1.64 & 5.92 \\
\hline Higher education & 22.78 & 10.54 & 19.61 & 0.82 & -0.49 \\
\hline Ratio of industry worker & 17.28 & 1.78 & 18.90 & 1.33 & -0.61 \\
\hline Agricultural Land & 6.20 & 31.38 & -1.17 & 25.47 & 11.50 \\
\hline (Agricultural Land)2 & -1.45 & -13.11 & -0.26 & -6.94 & -3.91 \\
\hline Sylvicultural Land & -0.13 & 0.78 & 9.11 & 0.68 & 7.22 \\
\hline (Sylvicultural Land)2 & 0.23 & 2.40 & -1.23 & -0.38 & -4.52 \\
\hline Aquacultural Land & 3.18 & 0.67 & 0.45 & 984.67 & 4.52 \\
\hline (Aquacultural Land)2 & -1.08 & -0.21 & -0.11 & -969.89 & -1.54 \\
\hline Remittance & 0.36 & 0.33 & 0.89 & -0.12 & -0.10 \\
\hline Permanent & 13.69 & 7.99 & 8.60 & 7.49 & 19.48 \\
\hline Semi-Permanent & 2.05 & 8.93 & 7.94 & 14.12 & 5.45 \\
\hline Inland Delta & 1.13 & -1.03 & -2.21 & - & - \\
\hline Hills & - & - & -0.49 & 0.50 & 0.42 \\
\hline Mountains & 3.30 & 5.04 & 6.39 & -0.28 & 39.63 \\
\hline Remoteness & 0.32 & 2.21 & 3.15 & 18.00 & -2.63 \\
\hline Road & 0.03 & 19.34 & 2.71 & 2.38 & 2.57 \\
\hline Transport & 1.84 & -0.03 & 0.00 & -0.54 & 5.07 \\
\hline Market & 3.29 & 0.06 & 0.41 & 0.40 & -1.21 \\
\hline Electricity & -0.09 & -1.29 & 7.93 & 7.98 & 4.28 \\
\hline SUM & 100 & 100 & 100 & 100 & 100 \\
\hline
\end{tabular}

Source: Authors' calculation

Proportion of factor contribution to total inequality in 2004

\begin{tabular}{cccccc}
\hline & Majority & Khmer minority & NU minority & CH minority & Other minority \\
\hline Age of household head & 6.83 & -13.88 & -5.99 & 2.57 & -5.56 \\
(Head age)2 & -2.90 & 17.39 & 3.88 & -2.43 & 9.84 \\
Female headship & 1.28 & 2.43 & 0.50 & 0.02 & 4.09 \\
Married & 0.61 & -1.95 & 0.06 & 0.93 & -2.36 \\
Share of female members & 2.41 & 4.57 & -0.10 & 28.69 & 0.30 \\
(Female share)2 & -2.02 & -4.40 & 0.89 & -14.97 & -0.22 \\
Dependency burden & 5.88 & 0.00 & 2.78 & -1.10 & 1.34 \\
Primary education & -1.25 & -0.04 & -8.46 & 1.91 & 0.19 \\
Secondary education & -2.37 & 3.80 & 15.17 & 6.39 & 2.43 \\
Higher education & 36.22 & 3.50 & 25.66 & 0.31 & 0.18 \\
Ratio of industry worker & 26.07 & 2.20 & 29.01 & 0.23 & 0.94 \\
Agricultural Land & 8.16 & 26.40 & -0.30 & -0.38 & 25.29 \\
(Agricultural Land)2 & -1.47 & 10.81 & 0.31 & 5.75 & -0.40
\end{tabular}




\begin{tabular}{|c|c|c|c|c|c|}
\hline Sylvicultural Land & 0.11 & 1.73 & 0.44 & -1.01 & 0.88 \\
\hline (Sylvicultural Land)2 & -0.07 & 0.82 & -0.01 & 0.76 & 0.06 \\
\hline Aquacultural Land & 1.50 & 39.32 & 3.89 & 44.83 & 2.19 \\
\hline (Aquacultural Land)2 & -0.51 & -13.10 & -1.53 & -40.87 & -1.18 \\
\hline Remittance & 0.56 & 0.51 & 1.47 & 2.08 & -3.93 \\
\hline Permanent & 16.41 & 0.34 & 9.35 & 0.02 & -0.02 \\
\hline Semi-Permanent & 1.36 & 4.53 & 5.60 & 28.69 & 31.08 \\
\hline Inland Delta & 0.85 & -0.06 & 1.52 & - & - \\
\hline Hills & 0.03 & - & 0.46 & 8.73 & 0.58 \\
\hline Mountains & 0.03 & 0.30 & 3.67 & -1.34 & 0.61 \\
\hline Remoteness & -0.20 & 2.79 & 3.11 & 27.20 & -0.08 \\
\hline Road & 0.17 & 10.25 & -0.51 & -0.19 & 8.42 \\
\hline Transport & 2.25 & 0.48 & 3.41 & -0.39 & 1.09 \\
\hline Market & 0.05 & 1.26 & 0.84 & 5.59 & 12.59 \\
\hline Electricity & -0.01 & - & 4.89 & -2.01 & 11.66 \\
\hline SUM & 100 & 100 & 100 & 100 & 100 \\
\hline
\end{tabular}

Source: Authors' calculation

Proportion of factor contribution to total inequality in 2006

\begin{tabular}{|c|c|c|c|c|c|}
\hline & Majority & Khmer minority & NU minority & CH minority & Other minority \\
\hline Age of household head & -7.40 & 10.31 & -2.73 & 0.59 & -4.49 \\
\hline (Head age) 2 & 5.65 & -15.45 & 1.18 & -1.78 & 2.84 \\
\hline Female headship & 0.44 & 8.04 & -0.03 & 3.20 & 0.61 \\
\hline Married & 0.41 & -0.27 & 0.16 & 5.22 & 2.14 \\
\hline Share of female members & 0.54 & 2.63 & -2.98 & -2.12 & -0.77 \\
\hline (Female share) 2 & -0.24 & -0.33 & 5.09 & 3.94 & 0.97 \\
\hline Dependency burden & 23.04 & 1.06 & 14.75 & 15.58 & 7.31 \\
\hline Primary education & -1.92 & -10.55 & 6.95 & 25.00 & 6.08 \\
\hline Secondary education & -3.31 & 7.73 & 0.22 & -13.53 & 2.98 \\
\hline Higher education & 29.42 & 10.24 & 14.10 & -0.48 & 0.00 \\
\hline Ratio of industry worker & 16.81 & -0.02 & 23.35 & -1.19 & 23.15 \\
\hline Agricultural Land & 24.20 & 41.69 & -3.02 & 5.73 & -0.49 \\
\hline (Agricultural Land)2 & -6.60 & -4.60 & 2.24 & 0.06 & -0.02 \\
\hline Sylvicultural Land & -0.02 & -4.56 & -0.79 & 9.44 & 28.12 \\
\hline (Sylvicultural Land)2 & 0.07 & 5.38 & 1.65 & -4.16 & -18.28 \\
\hline Aquacultural Land & 5.02 & 38.07 & 6.43 & 0.03 & 2.29 \\
\hline (Aquacultural Land)2 & -1.72 & -25.03 & -2.71 & 0.00 & -1.83 \\
\hline Remittance & 1.16 & 0.63 & 1.75 & -0.04 & 1.00 \\
\hline Permanent & 12.13 & 0.05 & 11.32 & 7.59 & 8.90 \\
\hline Semi-Permanent & -1.76 & 11.90 & 5.11 & 4.43 & 1.84 \\
\hline Inland Delta & 1.68 & 0.39 & -0.37 & - & -14.62 \\
\hline Hills & -0.01 & -0.42 & 0.34 & - & - \\
\hline Mountains & -0.47 & 0.34 & 3.38 & 1.05 & 26.45 \\
\hline Remoteness & 0.08 & 5.45 & 5.36 & 42.57 & -0.86 \\
\hline Road & 0.14 & -1.11 & 0.41 & -0.11 & -0.14 \\
\hline Transport & 1.47 & 6.04 & 4.04 & -1.03 & -0.28 \\
\hline Market & 1.02 & 12.42 & 0.21 & 0.02 & 4.68 \\
\hline Electricity & 0.15 & - & 4.62 & - & 22.42 \\
\hline SUM & 100 & 100 & 100 & 100 & 100 \\
\hline
\end{tabular}

Source: Authors' calculation 


\section{Appendix B.}

Descriptions of variables and mean values in 2002

\begin{tabular}{|c|c|c|c|c|c|c|}
\hline Variable & & Majority & $\begin{array}{c}\text { Khmer } \\
\text { minority }\end{array}$ & $\begin{array}{c}\mathrm{NU} \\
\text { minority }\end{array}$ & $\begin{array}{c}\mathrm{CH} \\
\text { minority }\end{array}$ & $\begin{array}{c}\text { Other } \\
\text { minority }\end{array}$ \\
\hline $\log$ (Consumption) & Log of per capita household expenditure & 7.824 & 7.518 & 7.390 & 7.120 & 7.033 \\
\hline Age of household head & Age of a household's head & 47.569 & 49.213 & 42.871 & 45.977 & 46.016 \\
\hline Female headship & Sex of a household's head & 0.172 & 0.246 & 0.067 & 0.085 & 0.084 \\
\hline Married & Whether the household head has a spouse & 0.861 & 0.783 & 0.944 & 0.903 & 0.888 \\
\hline Share of female members & Share of number of females in total household members & 0.505 & 0.501 & 0.494 & 0.492 & 0.499 \\
\hline Dependency burden & $\begin{array}{l}\text { Share of household members under } 15 \text { years old or above } 65 \text { years } \\
\text { old in total household members } \\
\text { Whether the highest degree of education attained by any household }\end{array}$ & 0.389 & 0.434 & 0.422 & 0.507 & 0.491 \\
\hline Primary education & member was from primary school or not & 0.250 & 0.479 & 0.341 & 0.404 & 0.333 \\
\hline Secondary education & $\begin{array}{l}\text { Whether the highest degree of education attained by any household } \\
\text { member was from secondary school or not }\end{array}$ & 0.588 & 0.202 & 0.415 & 0.182 & 0.180 \\
\hline Higher education & $\begin{array}{l}\text { Whether the highest degree of education attained by any household } \\
\text { member was from technical school/University or not } \\
\text { Share of members who are working in industry sector to total }\end{array}$ & 0.097 & 0.023 & 0.062 & 0.021 & 0.028 \\
\hline Ratio of industry worker & household members & 0.932 & 0.493 & 0.218 & 0.072 & 0.230 \\
\hline Agricultural Land & Area of agricultural land owned by household $\left(\right.$ million $\mathrm{m}^{2}$ ) & 0.0050 & 0.0081 & 0.00924 & 0.0141 & 0.01573 \\
\hline Sylvicultural Land & Area of sylvicultural land owned by household (million $\mathrm{m}^{2}$ ) & 0.0006 & 0.00021 & 0.01017 & 0.00669 & 0.00070 \\
\hline Aquacultural Land & Area of aquacultural land owned by household (million $\mathrm{m}^{2}$ ) & 0.0004 & 0.00001 & 0.00017 & 0.00069 & 0.00003 \\
\hline Permanent & Whether household lives in permanent house or not & 0.138 & 0.029 & 0.042 & 0.030 & 0.052 \\
\hline Semi-Permanent & Whether household lives in semi-permanent house or not & 0.615 & 0.230 & 0.630 & 0.501 & 0.542 \\
\hline Inland Delta & Whether the household is located in Inland Delta & 0.651 & 0.858 & 0.013 & 0.002 & 0.071 \\
\hline Hills & Whether the household is located in Hills & 0.080 & 0.000 & 0.024 & 0.030 & 0.001 \\
\hline Mountains & Whether the household is located in Mountains & 0.187 & 0.077 & 0.961 & 0.968 & 0.927 \\
\hline Remoteness & Whether the household resides in the remote area & 0.128 & 0.625 & 0.554 & 0.570 & 0.788 \\
\hline Road & $\begin{array}{l}\text { Whether the household belongs to the commune with the access to } \\
\text { the road or not } \\
\text { Whether the household belongs to the commune with the access to }\end{array}$ & 0.863 & 0.728 & 0.824 & 0.878 & 0.871 \\
\hline Transport & $\begin{array}{l}\text { the public transports or not } \\
\text { Whether the household belongs to the commune with the access to }\end{array}$ & 0.433 & 0.625 & 0.185 & 0.269 & 0.213 \\
\hline Market & $\begin{array}{l}\text { the market or not } \\
\text { Whether the household belongs to the commune with power supply }\end{array}$ & 0.571 & 0.441 & 0.294 & 0.214 & 0.296 \\
\hline Electricity & or not & 0.981 & 0.943 & 0.616 & 0.707 & 0.662 \\
\hline
\end{tabular}




\begin{tabular}{|c|c|c|c|c|c|c|}
\hline & & Majority & $\begin{array}{c}\text { Khmer } \\
\text { minority }\end{array}$ & NU minority & CH minority & $\begin{array}{c}\text { Other } \\
\text { minority }\end{array}$ \\
\hline $\log$ (Consumption) & Log of per capita household expenditure & 8.071 & 7.831 & 7.542 & 7.265 & 7.366 \\
\hline Age of household head & Age of a household's head & 48.978 & 52.301 & 43.862 & 45.520 & 48.622 \\
\hline Female headship & Sex of a household's head & 0.177 & 0.219 & 0.064 & 0.070 & 0.149 \\
\hline Married & Whether the household head has a spouse & 0.854 & 0.743 & 0.939 & 0.942 & 0.861 \\
\hline Share of female members & Share of number of females in total household members & 0.503 & 0.479 & 0.491 & 0.509 & 0.499 \\
\hline Primary education & member was from primary school or not & 0.217 & 0.331 & 0.305 & 0.431 & 0.362 \\
\hline Secondary education & $\begin{array}{l}\text { Whether the highest degree of education attained by any household } \\
\text { member was from secondary school or not }\end{array}$ & 0.556 & 0.401 & 0.473 & 0.180 & 0.241 \\
\hline Higher education & $\begin{array}{l}\text { Whether the highest degree of education attained by any household } \\
\text { member was from technical school/University or not } \\
\text { Share of members who are working in industry sector to total }\end{array}$ & 0.182 & 0.060 & 0.120 & 0.059 & 0.042 \\
\hline Ratio of industry worker & household members & 0.229 & 0.103 & 0.059 & 0.040 & 0.021 \\
\hline Agricultural Land & Area of agricultural land owned by household $\left(\right.$ million $\left.\mathrm{m}^{2}\right)$ & 0.00481 & 0.00782 & 0.00851 & 0.01408 & 0.01881 \\
\hline Sylvicultural Land & Area of sylvicultural land owned by household (million $\mathrm{m}^{2}$ ) & 0.00063 & 0.00015 & 0.00679 & 0.003043 & 0.00115 \\
\hline Aquacultural Land & Area of aquacultural land owned by household (million $\mathrm{m}^{2}$ ) & 0.00044 & 0.00072 & 0.00006 & 0.000001 & 0.00001 \\
\hline Remittance & Whether households have a remittance from domestic/overseas & 0.895 & 0.888 & 0.766 & 0.896 & 0.820 \\
\hline Permanent & Whether household lives in permanent house or not & 0.168 & 0.060 & 0.059 & 0.006 & 0.019 \\
\hline Semi-Permanent & Whether household lives in semi-permanent house or not & 0.637 & 0.259 & 0.623 & 0.516 & 0.541 \\
\hline Inland Delta & Whether the household is located in Inland Delta & 0.649 & 0.705 & 0.011 & 0.003 & 0.031 \\
\hline Hills & Whether the household is located in Hills & 0.083 & 0.000 & 0.016 & 0.013 & 0.028 \\
\hline Mountains & Whether the household is located in Mountains & 0.188 & 0.134 & 0.971 & 0.984 & 0.940 \\
\hline Remoteness & Whether the household resides in the remote area & 0.150 & 0.647 & 0.532 & 0.603 & 0.758 \\
\hline Road & $\begin{array}{l}\text { Whether the household belongs to the commune with the access to } \\
\text { the road or not } \\
\text { Whether the household belongs to the commune with the access to }\end{array}$ & 0.885 & 0.724 & 0.816 & 0.887 & 0.905 \\
\hline Transport & $\begin{array}{l}\text { the public transports or not } \\
\text { Whether the household belongs to the commune with the access to }\end{array}$ & 0.511 & 0.512 & 0.324 & 0.362 & 0.294 \\
\hline Market & $\begin{array}{l}\text { the market or not } \\
\text { Whether the household belongs to the commune with power supply }\end{array}$ & 0.687 & 0.725 & 0.413 & 0.180 & 0.366 \\
\hline Electricity & or not & 0.998 & 1.000 & 0.882 & 0.975 & 0.874 \\
\hline
\end{tabular}




\begin{tabular}{|c|c|c|c|c|c|c|}
\hline & & Majority & $\begin{array}{c}\text { Khmer } \\
\text { minority }\end{array}$ & NU minority & CH minority & $\begin{array}{c}\text { Other } \\
\text { minority }\end{array}$ \\
\hline $\log$ (Consumption) & Log of per capita household expenditure & 8.367 & 8.119 & 7.896 & 7.671 & 7.571 \\
\hline Age of household head & Age of a household's head & 48.828 & 52.348 & 43.939 & 44.809 & 47.601 \\
\hline Female headship & Sex of a household's head & 0.160 & 0.260 & 0.061 & 0.128 & 0.059 \\
\hline Married & Whether the household head has a spouse & 0.879 & 0.788 & 0.946 & 0.890 & 0.950 \\
\hline Share of female members & Share of number of females in total household members & 0.507 & 0.473 & 0.501 & 0.511 & 0.509 \\
\hline Primary education & member was from primary school or not & 0.197 & 0.659 & 0.327 & 0.551 & 0.362 \\
\hline Secondary education & $\begin{array}{l}\text { Whether the highest degree of education attained by any household } \\
\text { member was from secondary school or not }\end{array}$ & 0.588 & 0.286 & 0.507 & 0.402 & 0.590 \\
\hline Higher education & $\begin{array}{l}\text { Whether the highest degree of education attained by any household } \\
\text { member was from technical school/University or not } \\
\text { Share of members who are working in industry sector to total }\end{array}$ & 0.210 & 0.044 & 0.161 & 0.030 & 0.048 \\
\hline Ratio of industry worker & household members & 0.218 & 0.122 & 0.067 & 0.036 & 0.046 \\
\hline Agricultural Land & Area of agricultural land owned by household (million $\mathrm{m}^{2}$ ) & 0.0058 & 0.00894 & 0.00869 & 0.01539 & 0.01908 \\
\hline Sylvicultural Land & Area of sylvicultural land owned by household (million $\mathrm{m}^{2}$ ) & 0.0007 & 0.00045 & 0.00845 & 0.00083 & 0.00184 \\
\hline Aquacultural Land & Area of aquacultural land owned by household (million $\mathrm{m}^{2}$ ) & 0.0005 & 0.00103 & 0.00007 & 0.00000 & 0.00002 \\
\hline Remittance & Whether households have a remittance from domestic/overseas & 0.907 & 0.870 & 0.832 & 0.962 & 0.735 \\
\hline Permanent & Whether household lives in permanent house or not & 0.198 & 0.057 & 0.084 & 0.026 & 0.021 \\
\hline Semi-Permanent & Whether household lives in semi-permanent house or not & 0.664 & 0.318 & 0.662 & 0.681 & 0.763 \\
\hline Inland Delta & Whether the household is located in Inland Delta & 0.640 & 0.781 & 0.004 & 0.005 & 0.057 \\
\hline Hills & Whether the household is located in Hills & 0.085 & 0.014 & 0.013 & 0.000 & 0.022 \\
\hline Mountains & Whether the household is located in Mountains & 0.208 & 0.043 & 0.978 & 0.995 & 0.921 \\
\hline Remoteness & Whether the household resides in the remote area & 0.137 & 0.741 & 0.520 & 0.583 & 0.734 \\
\hline Road & $\begin{array}{l}\text { Whether the household belongs to the commune with the access to } \\
\text { the road or not } \\
\text { Whether the household belongs to the commune with the access to }\end{array}$ & 0.884 & 0.610 & 0.829 & 0.979 & 0.880 \\
\hline Transport & $\begin{array}{l}\text { the public transports or not } \\
\text { Whether the household belongs to the commune with the access to }\end{array}$ & 0.487 & 0.554 & 0.283 & 0.243 & 0.317 \\
\hline Market & $\begin{array}{l}\text { the market or not } \\
\text { Whether the household belongs to the commune with power supply }\end{array}$ & 0.378 & 0.400 & 0.154 & 0.170 & 0.395 \\
\hline Electricity & or not & 1.000 & 1.000 & 0.963 & 1.000 & 0.848 \\
\hline
\end{tabular}

